\title{
PRODUTIVIDADE E QUALIDADE FISIOLÓGICA DE SEMENTES DE MILHO- PIPOCA SUBMETIDO À APLICAÇÃO FOLIAR DE MOLIBDÊNIO
}

\section{YIELD AND PHYSIOLOGIC QUALITY OF POPCORN SEEDS, SUBMITTED TO MOLYBDENUM LEAF APPLICATION}

\author{
Geraldo Antonio de Andrade ARAÚJO' \\ André Ribeiro TEIXEIRA ${ }^{2}$ \\ Glauco Vieira MIRANDA ${ }^{1}$ \\ João Carlos Cardoso GALVÃO ${ }^{1}$ \\ Paulo Roberto Ribeiro ROCHA ${ }^{2}$
}

\begin{abstract}
RESUMO
O objetivo deste trabalho foi avaliar o efeito de doses crescentes de molibdênio na cultura do milho-pipoca, visando aumentar o teor deste nutriente nas sementes, a influência na qualidade fisiológica das sementes e a produtividade da cultura. Foi conduzido um experimento em campo, no delineamento de blocos ao acaso, com quatro repetições e sete doses de molibdênio $\left(0,50,100,200,400,800\right.$ e $\left.1600 \mathrm{~g} \mathrm{ha}^{-1}\right)$. As doses de $0,50,100,200 \mathrm{e} 400 \mathrm{~g} \mathrm{ha}^{-1}$, foram aplicadas de uma só vez aos 15 dias após emergência das plântulas, (DAE); a dose de $800 \mathrm{~g} \mathrm{ha}^{-1}$ foi aplicada em três parcelas, sendo $400 \mathrm{~g}$ aos $15 \mathrm{DAE}, 200 \mathrm{~g}$ aos 20 DAE e $200 \mathrm{~g}$ aos 25 DAE e a dose de $1600 \mathrm{~g} \mathrm{ha}^{-1}$ parcelada em quatro vezes iguais de $400 \mathrm{~g} \mathrm{ha}^{-1}$ aos $15,20,25$ e 30 DAE. Foram avaliados os componentes de produtividade, os teores dos nutrientes nas folhas e nas sementes e a qualidade fisiológica das sementes do milho-pipoca. O teor de molibdênio nas folhas e nas sementes foram influenciados pela aplicação deste micronutriente, atingindo valores máximos com a maior dose aplicada. O número total de sementes por parcela e a produtividade também foram influenciados pela aplicação de molibdênio atingindo valores máximos de 21448 sementes e $4250 \mathrm{~kg} \mathrm{ha}^{-1}$, com as doses de $680 \mathrm{~g} \mathrm{ha}^{-1}$ e $1600 \mathrm{~g} \mathrm{ha}^{-1}$, respectivamente. Doses de molibdênio até $1600 \mathrm{~g} \mathrm{ha}^{-1}$ não alterou a qualidade fisiológica das sementes de milho-pipoca.

Palavras-chaves: Adubação; molibdênio; sementes; Zea mays $L$.
\end{abstract}

\begin{abstract}
The goal of this work was to evaluate the effects of molybdenum increasing doses in popcorn crop, aiming to increasing the nutrient content in seeds, the influence of seed physiological quality and the crop yield. A field experiment was performed in a randomized block design, with four replications of seven doses of molybdenum $(0,50,100,200,400,800$ and $1600 \mathrm{~g} \mathrm{ha}^{-1}$ ). The doses of $0,50,100,200$ and $400 \mathrm{~g} \mathrm{ha}^{-1}$ were applied 15 days after seedling emergence (DAE), the dose of $800 \mathrm{~g} \mathrm{ha}^{-1}$ were applied in three portions as following: $400 \mathrm{~g}$ at $15 \mathrm{DAE}, 200 \mathrm{~g}$ at 20 days and $200 \mathrm{~g}$ at $25 \mathrm{DAE}$; and the dose of $1600 \mathrm{~g} \mathrm{ha}^{-1}$ in four equal portions of $400 \mathrm{~g}$ at 15,20,25 and $30 \mathrm{DAE}$. Yield components, nutrient content in leaves and seeds, and the seed physiological quality of popcorn were evaluated. The molybdenum content in leaves and seeds were influenced by the application of this micronutrient, reaching maximum values with the higher dose. The total number of seeds per plot and the yield were also influenced by molybdenum application, reaching maximum values of 21448 seeds and 4250 $\mathrm{kg} \mathrm{ha}^{-1}$, with the doses of $680 \mathrm{~g} \mathrm{ha}^{-1}$ and $1600 \mathrm{~g} \mathrm{ha}^{-1}$, respectively. Molybdenum doses up to $1600 \mathrm{~g} \mathrm{ha}^{-1}$ did not change the physiological quality of popcorn seeds.
\end{abstract}

Key-words: Fertilization; molybdenum; seeds; Zea mays $L$.

\footnotetext{
${ }^{1}$ Professor, Departamento de Fitotecnia da Universidade Federal de Viçosa, Av. PH Rolfs s/n, CEP 36570-000.- Campus Universitário, Viçosa, Minas Gerais, Brasil. E-mail: garaujo@ufv.br, Autor para correspondência; glaucovmiranda@ufv.br; jgalvao@yahoo.com.br.

2 Pós-graduando em Fitotecnia, Departamento de Fitotecnia, Universidade Federal de Viçosa, Minas Gerais, Brasil. E-mail: deribeirot@gmail.com; pauloagro01@yahoo.com.br
} 
ARAÚJJ, G.A.A. et al. Produtividade e qualidade fisiológica de sementes...

\section{INTRODUÇÃO}

O milho-pipoca é alimento bastante apreciado no Brasil. Segundo Miranda et al., (2007), o consumo nacional de milho-pipoca está em torno de 65 a 70 mil t ano ${ }^{-1}$, sendo que 15 a 20 mil t deste mercado correspondem ao milho-pipoca importado. O valor de mercado deste tipo de grão por quilo é bem superior ao do milho comum.

A adubação é um dos fatores que mais contribui para o aumento da produtividade do milho, porém existem poucos estudos com micronutrientes na cultura do milho-pipoca. Dentre os micronutrientes o molibdênio (Mo) é o requerido em menor quantidade, sua principal função está associada ao metabolismo do nitrogênio $(\mathrm{N})$, e relaciona-se às enzimas redutase do nitrato e nitrogenase, de modo que os sintomas de deficiência de Mo confundem-se com os sintomas de deficiência de N (Marschner, 1995). Em plantas, nas quais não ocorre fixação simbiótica de $\mathrm{N}$, a essencialidade de Mo está relacionada à atividade da enzima nitrato redutase, responsável pela assimilação do nitrato pelas plantas, onde o Mo atua como doador de elétrons (Taiz \& Zeiger, 2006).

$\mathrm{O}$ Mo é requerido em pequenas quantidades pelas plantas, as concentrações adequadas para o crescimento das plantas variam entre 0,6 e $10 \mathrm{mg}$ $\mathrm{kg}^{-1}$ de Mo (Dechen \& Nachtigall, 2006). Dada à pequena quantidade demandada pelas plantas, a produção de sementes enriquecidas com Mo, pode ser a forma mais eficiente para suprimento das necessidades das plantas. As sementes com elevadas concentrações de Mo podem fornecer quantidades do nutriente suficientes para garantir um adequado crescimento às plantas, sem adição suplementar de Mo. A obtenção de sementes com essa característica é possível, uma vez que o Mo é translocado para esse órgão em quantidades correspondentes a sua concentração no tecido (Jacob-Neto \& Rossetto, 1998). Assim, o nutriente estaria disponível para a planta no momento em que a mesma necessitasse, evitando a ocorrência de deficiência mesmo por curto tempo. Além disso, seria eliminada a operação de aplicação do nutriente, reduzindo assim os custos de produção da cultura, incentivando também o uso de sementes de alta qualidade pelo produtor.

A influência de componentes químicos da semente sobre o seu vigor e potencial de armazenamento, torna fundamental o conhecimento da composição química desta (Carvalho \& Nakagawa, 2000). Vários autores citam a adubação como uma forma de aumentar o conteúdo de nutrientes nas sementes (Jacob-Neto \& Rosseto, 1998; Kubota et al., 2008).

Para que se consiga fornecer o Mo à planta, via conteúdo do nutriente na semente, faz-se necessária à determinação da dose suficiente para transportá-lo para este órgão nas quantidades desejadas. Esta tentativa foi realizada em pesquisa recente, sem, no entanto, obter resultados satisfatórios (Ferreira et al., 2003). Os resultados obtidos revelam a necessidade do uso de doses elevadas para que possa atingir tal finalidade. Com isso, o parcelamento dessas doses torna-se fundamental para se evitar injúrias à planta, não havendo, porém, recomendações concisas para esse parcelamento.

O objetivo deste trabalho foi avaliar o efeito de doses crescentes de molibdênio na cultura do milho-pipoca, visando aumentar o teor deste nutriente nas sementes, a influência na qualidade fisiológica das sementes e a produtividade da cultura.

\section{MATERIAL E MÉTODOS}

O experimento foi conduzido na estação experimental da Universidade Federal de Viçosa, localizada no município de Coimbra, na Zona da Mata de Minas Gerais, cujas coordenadas são $20^{\circ}$ 50 ' 30" latitude sul e $42^{\circ} 43^{\prime} 30^{\prime \prime}$ longitude oeste, com altitude de $715 \mathrm{~m}$, no período de outubro de 2003 a abril de 2004. A área experimental apresenta a topografia plana, sendo seu solo classificado como Argissolo Vermelho-Amarelo, fase terraço. Anteriormente à instalação do experimento, foram coletadas amostras de solo à profundidade de 0 a $20 \mathrm{~cm}$, para caracterização física e química de acordo com metodologia descrita pela EMBRAPA (1997), obtendo-se os resultados: $\mathrm{pH}$ em água $=5,60 ; \mathrm{P}=5,80 \mathrm{mg} \mathrm{dm}^{-3} ; \mathrm{K}$ $=18,00 \mathrm{mg} \mathrm{dm}^{-3} ; \mathrm{Al}^{3+}=0,00 \mathrm{cmol}_{\mathrm{c}} \mathrm{dm}^{-3} ; \mathrm{Ca}^{2+}=1,90$ $\mathrm{cmol}_{\mathrm{c}} \mathrm{dm}^{-3} ; \mathrm{Mg}^{2+}=0,60 \mathrm{cmol}_{\mathrm{c}} \mathrm{dm}^{-3-} ; \mathrm{Zn}^{2+}=23,30$ $\mathrm{mg} \mathrm{dm}{ }^{-3} ; \mathrm{H}+\mathrm{Al}^{+}=4,20 \mathrm{cmol}_{\mathrm{c}} \mathrm{dm}^{-3} ; \mathrm{SB}^{+}=2,57 \mathrm{cmol}_{\mathrm{c}}$ $\mathrm{dm}^{-3}$; Saturação de bases $(V)=37,90 \%$; Saturação de alumínio $(\mathrm{m})=0,00 \% ; \mathrm{C}=1,75 \mathrm{dag} \mathrm{\textrm {kg } ^ { - 1 }}$ e a textura do solo classificada como argilosa (580 g $\mathrm{kg}^{-1}$ de argila)

O delineamento utilizado foi o de blocos ao acaso com quatro repetições, e sete tratamentos, constituídas pelas doses de molibdênio $(0,50,100$, $\left.200,400,800,1600 \mathrm{~g} \mathrm{ha}^{-1}\right)$. Cada parcela foi constituída de cinco fileiras de cinco metros de comprimento, espaçadas $0,90 \mathrm{~m}$ entre si, sendo a área útil de $9 \mathrm{~m}^{2}$ representada por duas fileiras centrais. A população foi de 55000 plantas ha ${ }^{-1}$. Utilizou-se a cultivar de milho-pipoca UFVM 2, cultivado no período de outubro de 2003 a abril de 2004.

O preparo do solo para a condução do experimento foi de forma convencional, com uma aração e duas gradagem, os tratos culturais realizados foram os normais para a cultura do milho-pipoca. A adubação de plantio foi realizada de acordo a recomendação para a cultura do milho (Alves et al., 1999), esta constituiu-se de $420 \mathrm{~kg} \mathrm{ha}$

da formulação 8-28-6 $\left(\mathrm{N}-\mathrm{P}_{2} \mathrm{O}_{5}-\mathrm{K}_{2} \mathrm{O}\right)$, sendo que não se realizou adubação de cobertura com nitrogênio.

O molibdênio foi aplicado via foliar, tendo como fonte o molibdato de amônio $\left(540 \mathrm{~g} \mathrm{~kg}^{-1} \mathrm{de}\right.$ Mo). As doses foram aplicadas da seguinte forma: $0,50,100,200$ e $400 \mathrm{~g} \mathrm{ha}^{-1}$, aplicadas de uma só vez aos 15 dias após emergência das plântulas, (DAE); a dose de $800 \mathrm{~g} \mathrm{ha}^{-1}$ foi aplicada em três vezes, sendo $400 \mathrm{~g}$ aos $15 \mathrm{DAE}, 200 \mathrm{~g}$ aos $20 \mathrm{DAE}$ 
ARAÚJO, G.A.A. et al. Produtividade e qualidade fisiológica de sementes...

e $200 \mathrm{~g}$ aos 25 DAE e a dose de $1600 \mathrm{~g} \mathrm{ha}^{-1}$ parcelada em quatro vezes iguais aos 15, 20, 25 e 30 DAE.

Para a aplicação do molibdênio utilizou-se pulverizador costal pressurizado com $\mathrm{CO} 2$ mantido a pressão constante $\left(3,0 \mathrm{kgf} \mathrm{cm}^{-2}\right)$ munido com bico tipo leque 110.02, espaçados de $0,5 \mathrm{~m}$ entre si, o volume de calda foi de $200 \mathrm{~L} \mathrm{ha}^{-1}$.

Foram realizadas as seguintes avaliações: o índice SPAD (Minolta -502), nas folhas; altura de plantas e inserção de espigas; número de plantas acamadas e quebradas; estande final (número de plantas $\mathrm{ha}^{-1}$ ); número total de sementes por parcela; massa de 1000 grãos; produtividade; massa hectolítrica.

Em laboratório foram avaliados os teores de $\mathrm{N}$ orgânico, $\mathrm{P}, \mathrm{K}, \mathrm{Ca}, \mathrm{Mg}, \mathrm{S}$ e $\mathrm{Mo}$, nas folhas e nas sementes. As folhas utilizadas para análise foram coletadas durante a fase de floração, onde foram coletadas cinco folhas por parcela, sendo uma folha por planta, utilizando-se a terceira fileira e a folha oposta e abaixo da espiga (Martinez et al. 1999). Logo após a coleta, as folhas foram colocadas para secar em estufa de ventilação forçada, a $70{ }^{0} \mathrm{C}$, até atingir massa constante, sendo posteriormente moídas. O teor de N-orgânico foi determinado pelo método do reagente de Nesseler (Jackson, 1958). Após digestão nítricoperclórica determinou-se o $\mathrm{K}$ por fotometria de chama (Sarruge \& Haag, 1974); o Ca e Mg por espectrofotometria de absorção atômica (AOAC,1975); o P em espectrofotômetro pelo método da vitamina $\mathrm{C}$, modificado por Braga \& Defelipo (1974); e o S por turbidimetria do sulfato (Jackson, 1958). Para análise do molibdênio foi utilizado o Método do lodeto de Potássio (Fontes et al. 2000).

Para verificação da qualidade fisiológica de sementes foi realizado testes de germinação e vigor. A germinação foi determinada pelo Teste Padrão de Germinação e Germinação em areia de acordo com BRASIL (1992). Na determinação do vigor foram utilizados os testes de condutividade elétrica (AOSA, 1983), Teste de Envelhecimento acelerado, pelo Método do Gerbox, adotado pela AOSA (1983), Índice de Velocidade de Germinação (IVG), realizado juntamente com o Teste de Germinação em areia (AOSA, 1983).

Todos os dados, em percentagem, foram transformados em arcsen $(x)^{1 / 2}$ dado em $\% / 100$, antes de serem submetidos à análise de variância pelo teste $\mathrm{F}$. Em caso de significância, os dados foram submetidos à análise de regressão.

\section{RESULTADOS E DISCUSSÃO}

Os resultados referentes às características de altura de plantas (média de 2,44 m), altura de inserção de espigas (média de 1,13 m), número de plantas por parcela (média de 34,25 plantas parcela $^{-1}$ ), número de plantas acamadas (média de 4,26 plantas parcela ${ }^{-1}$ ), número de plantas quebradas (média de 4,33 plantas parcela ${ }^{-1}$ ), massa hectolítrica (média de $83,25 \mathrm{~kg} \mathrm{hL}^{-1}$ ), número de espigas por planta (média de 1,25 espigas) e estande final de plantas (média de 47.595 plantas $\mathrm{ha}^{-1}$ ), não foram observados efeitos da aplicação de molibdênio nestas características. Estas características podem ser alteradas quando ocorre algum desequilíbrio nutricional, fato não observado no experimento, mesmo com aplicação de doses crescentes e elevadas de molibdênio. Não foi observado efeito fitotóxico do Mo a cultura, mesmo quando aplicada dose elevada deste micronutriente (1600 $\left.\mathrm{g} \mathrm{ha}^{-1}\right)$. Ferreira et al. (2001) aplicando a dose única de $90 \mathrm{~g}$ de $\mathrm{Mo} \mathrm{ha}^{-1}$ em milho comum, observou que esta dose não influenciou a altura de plantas, número de plantas por parcela, número de plantas acamadas e quebradas. Estes autores justificam a ausência de resposta da adubação com molibdênio, por este nutriente no solo estar, provavelmente, com teor satisfatório para o desenvolvimento da cultura, e outra explicação é que o teor de molibdênio nas sementes plantadas seria suficiente para o desenvolvimento normal das plantas.

O índice SPAD, a massa de 1000 grãos, assim como a capacidade de expansão do milhopipoca, também não foram influenciados pela aplicação de doses de molibdênio. O índice SPAD avaliado aos 30,40 e 50 DAE foram de 41,64; 47,89 e 49,22 respectivamente. A média massa de 1000 grãos para as peneiras de $15,14,13,12$ foram de 125,73; 105,9; 91,29 e 66,71 g, respectivamente. Para a capacidade de expansão as médias foram: 20,$67 ; 22,45 ; 23 ; 42$ e 22,86 volume por peso, para as peneiras de 15, 14, 13 e 12.

Os teores foliares e nas sementes, dos macronutrientes no milho-pipoca não foram influenciados com a aplicação das doses de molibdênio. Os teores foliares $\mathrm{NH}_{4}^{+}, \mathrm{P}, \mathrm{K}, \mathrm{Ca}, \mathrm{Mg}$ e $S$ do milho-pipoca foram de: 25,$6 ; 2,3 ; 13,5 ; 5,2$; 3,$4 ; 1,2 \mathrm{~g} \mathrm{~kg}^{-1}$ respectivamente. Nas sementes os teores $\mathrm{NH}_{4}^{+}, \mathrm{P}, \mathrm{K}, \mathrm{Ca}, \mathrm{Mg}$ e $\mathrm{S}$ os teores foram de: 18,$0 ; 7,3 ; 8,3 ; 0,02$ e 2,9 respectivamente. Estes teores foliares dos nutrientes analisados estão dentro da faixa considerada satisfatória para o bom desenvolvimento do milho de acordo com Martinez et al., (1999). O efeito positivo da adubação molíbdica no milho, sobre os teores foliares de nitrogênio orgânico foi relatado por alguns autores (Coelho et al., 1998; Valentini et al., 2005), estes atribuíram este aumento do nitrogênio orgânico devido a uma maior atividade da enzima redutase do nitrato.

Ferreira et al. (2001) não observaram influência da adubação molíbdica nos teores dos nutrientes quando aplicou $90 \mathrm{~g}$ de $\mathrm{Mo} \mathrm{ha}^{-1}$ no milho comum. Na cultura do feijoeiro, Pessoa et al. (2000) trabalhando com doses de Mo observaram acréscimos nos níveis de $\mathrm{N}$ e $\mathrm{Mo}$, não havendo aumentos nos teores de $\mathrm{P}$ e $\mathrm{Cu}$ nas folhas, nem para os de $\mathrm{P}, \mathrm{Ca}, \mathrm{Mg}$ e $\mathrm{Mn}$ nos grãos, mas observaram resposta quadrática negativa na concentração dos nutrientes $\mathrm{K}, \mathrm{Ca}, \mathrm{Mg}, \mathrm{Fe}, \mathrm{Mn}$ e $\mathrm{Zn}$, nas folhas, e de $\mathrm{K}, \mathrm{Fe}, \mathrm{Zn}$ e $\mathrm{Cu}$, nos grãos, com a aplicação de dose crescentes de molibdênio. 
ARAÚJO, G.A.A. et al. Produtividade e qualidade fisiológica de sementes...

Tanto o teor de molibdênio foliar como nas sementes aumentaram significativamente de forma linear com aplicação do micronutriente (Figuras $1 \mathrm{e}$ 2), as doses de molibdênio estudas não foram suficientes para atingir o máximo deste micronutriente nas folhas e nas sementes, é interessante salientar que mesmo na dose mais elevada $\left(1.600 \mathrm{~g} \mathrm{ha}^{-1}\right)$, este micronutriente não se apresentou tóxico às plantas de milho-pipoca, indicando assim que esta cultura pode tolerar doses mais elevadas deste nutriente. Brodrick et al., (1992) observaram que a concentração de Mo em sementes de feijão também aumentou em resposta a aplicação foliar deste elemento, o que evidência a capacidade de translocação e a capacidade delas em armazenar este micronutriente, o que é importante para garantir a demanda inicial em Mo pelas plantas, podendo até prevenir possíveis deficiências. Vieira et al. (2002) estudando altas doses de Mo (1.440 $\mathrm{g} \mathrm{ha}^{-1}$ ) na cultura do feijão, por meio de aplicações foliares, constataram que altas doses de Mo não foram tóxicas para a cultura, e que sementes provenientes destas plantas podem conter até 13 vezes mais Mo em relação àquelas que não receberam este tratamento.

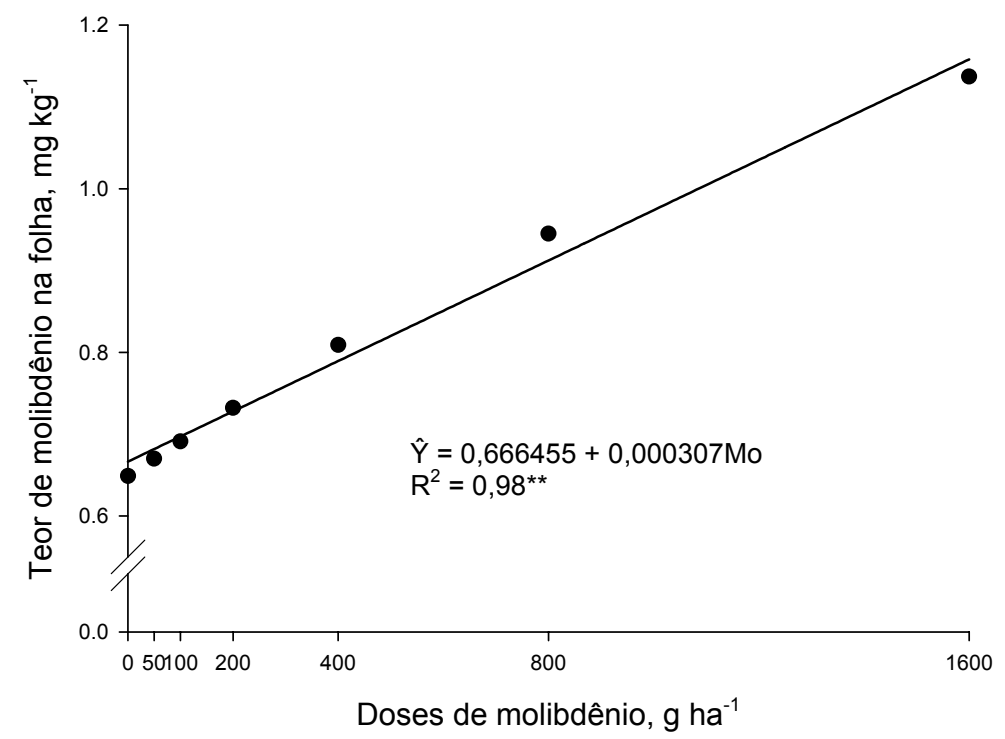

FIGURA 1 - Teor de Mo nas folhas de milho-pipoca, em função de doses de Mo, ** significativo a $1 \%$ de significância pelo teste F, Coimbra-MG, 2004.

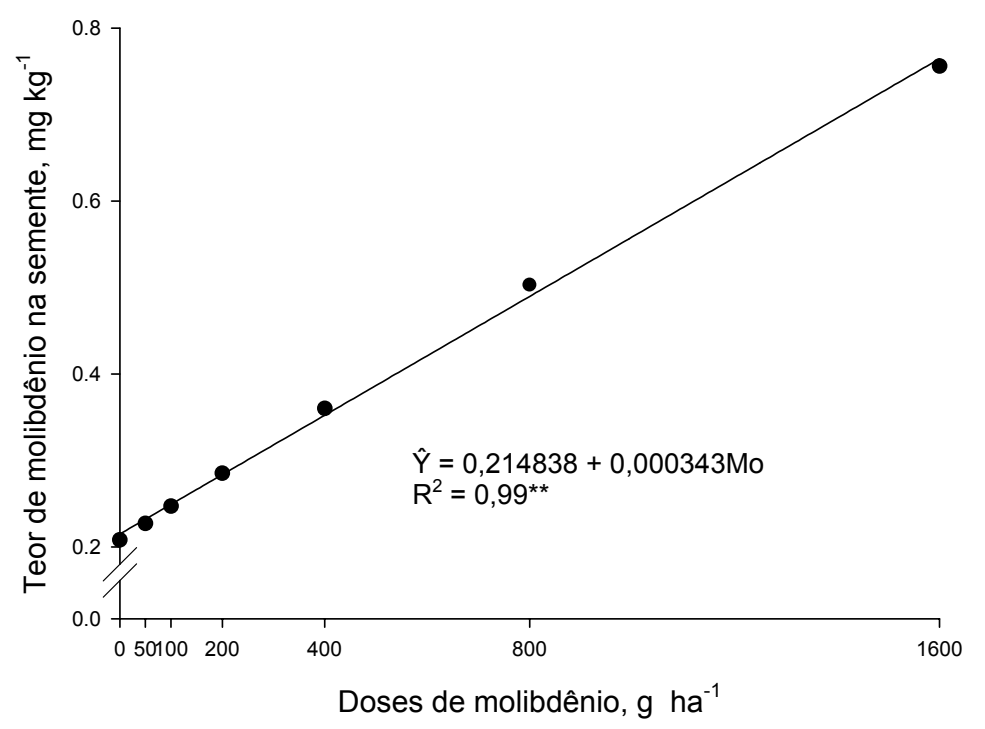

FIGURA 2 - Teor de Mo na semente de milho-pipoca, em função de doses de Mo, ${ }^{* *}$ significativo a $1 \%$ de significância pelo teste F, Coimbra-MG, 2004. 
ARAÚJO, G.A.A. et al. Produtividade e qualidade fisiológica de sementes...

O número total de sementes por parcela também foi influenciado significativamente pela aplicação de Mo, apresentando maior número de sementes com a dose estimada de $678 \mathrm{~g} \mathrm{ha}^{-1}$ (Figura 3).

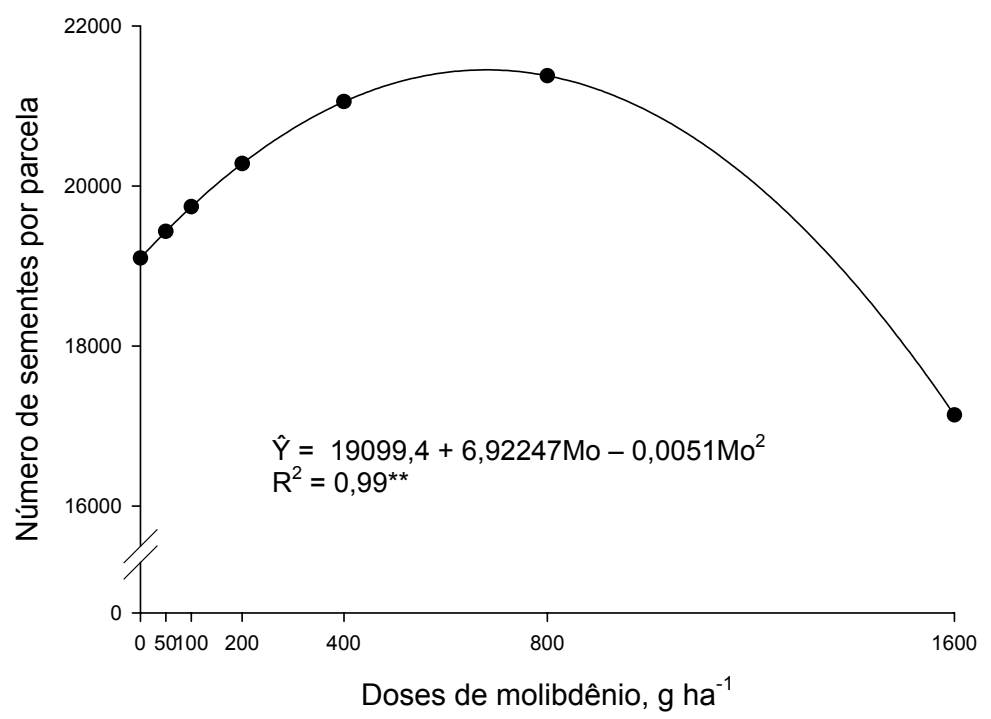

FIGURA 3 - Número total de sementes por parcela, em função de doses de Mo, ** significativo a $1 \%$ de significância pelo teste F, Coimbra-MG, 2004.

A produtividade de grãos aumentou, de forma linear com o incremento das doses de Mo (Figura 4). Dentro do intervalo de doses de Mo estudado, o acréscimo na produtividade foi de aproximadamente, $19 \%$. Este aumento na produtividade também foi observado por Valentini et al. (2005) para o milho comum estes autores observaram incremento na produtividade de até $43 \%$ com a aplicação do Mo na dose de $90 \mathrm{~g} \mathrm{ha}^{-1}$.

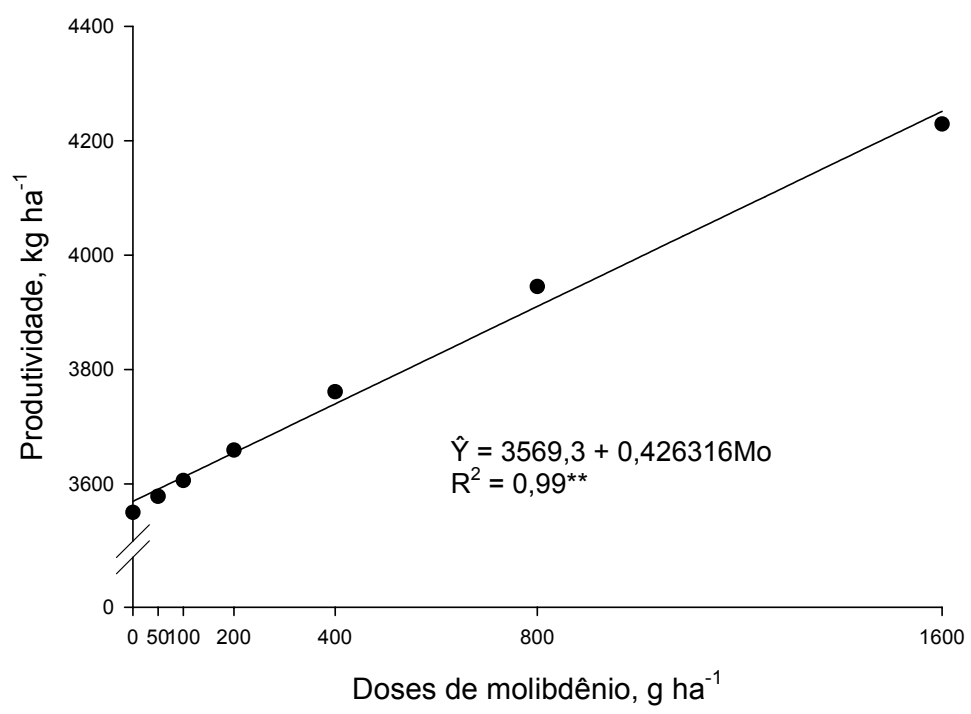

FIGURA 4 - Produtividade do milho-pipoca, em função de doses de Mo, ** significativo a 1\% de significância pelo teste F, Coimbra-MG, 2004. 
ARAÚJO, G.A.A. et al. Produtividade e qualidade fisiológica de sementes...

Com a aplicação de Mo, pode ter ocorrido um aumento da atividade da redutase do nitrato, enzima que contém molibdênio em sua estrutura e que participa diretamente do metabolismo do nitrogênio. O nitrogênio por sua vez, tem efeito direto na formação do grão de pólen e na redução do abortamento de óvulos, influenciando diretamente na formação dos grãos e refletindo na produtividade da cultura (Carvalho \& Nakagawa, 2000).

Com relação à qualidade fisiológica das sementes, pode-se dizer que as doses de Mo aplicadas não promoveram efeito significativo neste caractere avaliado, apresentando valores médios dos testes de germinação padrão (TPG), envelhecimento acelerado, condutividade elétrica, índice de velocidade de germinação e germinação em areia de $81,57 \% ; 75,86 \% ; 21,30 \mu \mathrm{cm}^{-1} \mathrm{~g}^{-1}$, 10,37 e $79 \%$ respectivamente.

Estes resultados corroboram com os de Ferreira et al. (2003), que avaliaram o efeito do conteúdo de molibdênio nas sementes de feijão e não obtiveram resposta significativa em relação à qualidade fisiológica de sementes para os testes de germinação (TPG), envelhecimento acelerado e primeira contagem do TPG, exceção feita para o teste de condutividade elétrica que apresentou resposta significativa para o conteúdo de Mo presente nas sementes.

Bassan et al. (2001) citam que a germinação de sementes de feijão Pérola foi prejudicada pela adubação molíbdica, tendo a dose de $75 \mathrm{~g} \mathrm{ha}^{-1}$ de Mo reduzido a germinação. Binneck et al. (1999) também não verificaram influência da adubação molíbdica na dose de 40 $\mathrm{mg} \mathrm{ha}^{-1}$ de Mo sobre a germinação de sementes de trevo-branco. Segundo Modi (2002), a aplicação de Mo influencia significativamente na germinação do trigo, ocorrendo prolongamento do período de dormência das sementes com maior conteúdo do micronutriente.

Efeito positivo do Mo sobre o vigor da semente tem sido relatado em trabalhos com feijão. Leite et al. (2009) observou que para os cultivares de feijão Novo Jalo e Meia Noite, tanto pelo envelhecimento acelerado quanto pela condutividade elétrica, o vigor foi significativamente influenciado pelo conteúdo de Mo na semente. As sementes produzidas sem adubação molíbdica apresentaram menor vigor em relação às produzidas com essa adubação.

\section{CONCLUSÕES}

1) A adubação com molibdênio promoveu, aumento dos teores deste elemento tanto na folha como nas sementes.

2) A produtividade do milho-pipoca foi aumentada, com o incremento das doses de molibdênio.

3) Doses de molibdênio até $1600 \mathrm{~g} \mathrm{ha}^{-1}$ não alterou a qualidade fisiológica das sementes de milho-pipoca.

\section{REFERÊNCIAS}

1. ASSOCIATION OF OFFICIAL ANALYTICAL CHEMISTS (AOAC). Official methods of analysis. 12. ed. Washington: The Association, 1975. $1094 \mathrm{p}$.

2. ASSOCIATION OF OFFICIAL SEED ANALYSTS (AOSA). Seed vigor testing handbook. East Lasing: The Association, 1983. 93 p. (Contribution, 32).

3. ALVES, V. M. C. et al. Milho. In: RIBEIRO, A.C.; GIMARÃES, P. T. G.; ALVAREZ, V. H. (Ed.) Recomendações para o uso de corretivos e fertilizantes em Minas Gerais. 5. aproximação, Viçosa: CFSEMG, 1999. p. 143-167.

4. BASSAN, D. A. Z. et al. Inoculação de sementes e aplicação de nitrogênio e molibdênio na cultura do feijão de inverno: produção e qualidade fisiológica de sementes. Revista Brasileira de Sementes, v. 23, n. 1, p. 76-83, 2001.

5. BINNECK, E.; BARROS, A. C. S. A.; VAHL, L. C. Peletização e aplicação de molibdênio em sementes de trevo branco. Revista Brasileira de Sementes, v. 21, n. 2, p. 203-207, 1999.

6. BRAGA, J. M.; DEFELIPO, B. V. Determinação espectrofotométrica de fósforo em extratos de solos e plantas. Revista Ceres, v. 21, n. 1, p.73-85, 1974

7. BRASIL. Regras para Análise de Sementes. Brasília: Ministério da Agricultura e Reforma Agrária. Secretaria Nacional de Defesa Agropecuária, 1992. $365 \mathrm{p}$.

8. BRODRICK, S. J.; SAKALA, M. K.; GILLER, K. E. . Molybdenum reserves of seed, and growth and $\mathrm{N}_{2}$ fixation by Phaseolus vulgaris L. Biology and Fertility of Soils, v. 13, n. 1, p. 39-44, 1992

9. CARVALHO, N. M.; NAKAGAWA, J. Sementes: ciência, tecnologia e produção. 4. ed. Jaboticabal: FUNEP, 2000. 588 p.

10. COELHO, F. C. et al. Nitrogênio e molibdênio nas culturas do milho e do feijão, em monocultivos e em consórcios: Efeitos sobre o milho. Revista Ceres, v. 45, n. 261, p. 479-498, 1998.

11. DECHEN, A. R.; NACHTIGALL, G. R. Micronutrientes. In: FERNANDES, M. S. (Ed.). Nutrição mineral de plantas. Viçosa: SBCS, 2006. p. 328-354.

12. EMPRESA BRASILEIRA DE PESQUISA AGROPECUÁRIA (EMBRAPA). Manual de métodos de análise de solo. 2. ed. Rio de Janeiro: EMBRAPA, 1997. 212 p.

13. FERREIRA, A. C. B. et al. Características agronômicas e nutricionais do milho adubado com nitrogênio, molibdênio e zinco. Scientia Agricola, v. 58, n. 1, p. 131-138, 2001.

14. FERREIRA, A. C. B. et al. Características agronômicas do feijoeiro em função do molibdênio contido na semente e da sua aplicação via foliar. Acta Scientiarum Agronomy, v. 25, n. 1, p. 65-72, 2003.

15. FONTES, R. L. F. et al. Determination of molybdenum in soil test extracts with potassium iodide plus hydrogen peroxide reaction. Communications in Soil Science and Plant Analysis, v. 31, n. 15/16, p. 2671-2683, 2000.

16. JACKSON, M. L. Nitrogen determinations for soil and plants tissue. In: JACKSON, M.L. (Ed.) Soil chemical analysis. Englewood Chiffis: Prentice Hall, 1958. p. 183-204.

17. JACOB-NETO, J.; ROSSETO, C. A. V. Concentração de nutrientes nas sementes. O papel do molibdênio. Floresta e Ambiente, v. 5, n. 1, p.171-183, 1998. 
ARAÚJO, G.A.A. et al. Produtividade e qualidade fisiológica de sementes...

18. KUBOTA, F. Y. et al. Crescimento e acumulação de nitrogênio de plantas de feijoeiro originadas de sementes com alto teor de molibdênio. Revista Brasileira de Ciência do Solo, v. 32, n. 4, p. 1635-1641, 2008.

19. LEITE, U.T. et al. Influência do conteúdo de molibdênio na qualidade fisiológica da semente de feijão: cultivares Novo Jalo e Meia Noite. Revista Ceres, v. 56, n. 2, p. 225-231, 2009.

20. MARTINEZ, H. E. P.; CARVALHO, J. G.; SOUZA, R. B. Diagnose foliar. In: RIBEIRO, A.C.; GIMARÃES, P. T. G.; ALVAREZ, V. H. Recomendações para o uso de corretivos e fertilizantes em Minas Gerais. (Ed.) 5. aproximação, Viçosa: CFSEMG, 1999. p. 143-167.

21. MARSCHNER, H. Mineral nutrition of higher plants. 2. ed. New York: Academic Press, 1995, $889 \mathrm{p}$.

22. MIRANDA, G. V.; SANTOS, I. C.; GALVÃO, J. C. C. Milho-pipoca ( Zea mays). In: PAULA JÚNIOR, T. J.; VENZON, M. (Org.). 101 culturas: manual de tecnologias agrícolas. Belo Horizonte: EPAMIG, 2007. p. 553-558.

23. MODI, A. Wheat seed quality in response to molybdenum and phosphorus. Journal of Plant Nutrition, v. 25, n. 11, p. 2409-2419, 2002

24. PESSOA, A. C. S. et al. Concentração foliar de molibdênio e exportação de nutrientes pelo feijoeiro "Ouro Negro" em resposta à adubação foliar com molibdênio. Revista Brasileira de Ciência do Solo, v. 24, n. 1, p. 75-84, 2000.

25. SARRUGE, J. R.; HAAG, H. P. Análises químicas em plantas. Piracicaba: ESALQ, Departamento de Química, 1974. 56 p.

26. VALENTINI, L. et al. Teor de nitrogênio foliar e produtividade de três cultivares de milho (Zea mays L.) submetidos às adubações nitrogenada e molíbdica. Revista Ceres, v. 52, n. 302, p. 567-577, 2005.

27. TAIZ, L.; ZEIGER, E. Plant physiology. 4. ed. Sunderland: Sinauer, 2006. 705 p.

28. VIEIRA, F.V.; SALGADO, L. T., RIGUEIRA, C. M. S. Produção de sementes de feijão com alto teor de molibdênio. In: CONGRESSO NACIONAL DE PESQUISA DE FEIJÃO, 7., 2002, Viçosa. Resumos... Viçosa: UFV, 2002. p. 530-533.

Recebido em 13/03/2009

Aceito em 26/04/2010 
